\title{
Áreas de preservação permanente e reserva legal: experiência em educação ambiental envolvendo famílias de produtores rurais
}

\author{
Permanent preservation areas and legal reserve: an experience in environmental education with farming families \\ Morgana Taís Streck' \& Liliana Essi² \\ I Acadêmica do Curso de Ciências Biológicas- Universidade Federal de Santa Maria, campus Palmeira das Missões/RS, executora do traba- \\ Iho e autora para correspondência - morganatstreck@gmail.com \\ 2 Docente da Universidade Federal de Santa Maria; orientadora - lili.essi@gmail.com
}

\begin{abstract}
Resumo
Áreas de Preservação Permanente (APPs) e Reserva Legal (RL) são áreas protegidas pelo Código Florestal Brasileiro que exercem importante papel na preservação ambiental. Foram realizadas atividades de conscientização ambiental nos Assentamentos Potreiro Bonito e Terra Nova, localizados no Município de Palmeira das Missões-RS, visando a promover e ampliar a troca de conhecimento sobre APPs e RLs e incentivar a conservação e recuperação destas áreas. A mobilização dos assentados para a participação nas atividades foi realizada com o auxílio da EMATER- Palmeira das Missões e as atividades constaram de palestras, questionamentos, troca de experiências e distribuição de mudas de árvores. Observou-se que os produtores reconhecem a importância da preservação das APPs e RLs, entretanto, não se sentem motivados a conservar tais áreas, por perceberem as áreas protegidas como áreas economicamente inativas. Essa dissonância entre o reconhecimento da importância da preservação das APPs na teoria, e a preocupação da perda de área agriculturável na prática evidencia a importância do investimento contínuo em educação ambiental, principalmente através de projetos e programas de longo prazo, para despertar o interesse dos assentados em participar diretamente de um processo produtivo em harmonia com o meio ambiente.
\end{abstract}

Palavras Chave: assentamentos, mata ciliar, código florestal, legislação ambiental, desenvolvimento sustentável

\begin{abstract}
Permanent Preservation Areas (APPs) and Legal Reserve (RL) are areas protected by the Brazilian Forest Code that play an important role in environmental conservation. Environmental awareness activities were conducted in the Settlements Potreiro Bonito and Terra Nova, located in the City of Palmeira das Missões-RS, to promote and expand the exchange of knowledge about APP and RL, and to encourage the conservation and recovery of these areas. The mobilization of settlers for participation in activities was performed with the aid of EMATER - Palmeira das Missões and the activities consisted of lectures, questions, exchange of experiences and distribution of tree seedlings. It was observed that producers recognize the importance of preserving the APPs and RLs, however, do not feel motivated to conserve such areas, because they perceive protected areas as areas economically inactive. This dissonance between the recognition of the importance of preserving the APPs in theory, and the concern of the loss of agricultural area in practice, highlights the importance of continued investment in environmental education, primarily through projects and long-term programs, to arouse the interest of the settlers on participate directly in a production process in harmony with the environment.
\end{abstract}

Keywords: settlements, riparian forest, forest code, environmental legislation, sustainable development 


\section{INTRODUÇÃO}

Embora a legislação ambiental seja um assunto de grande importância e destaque na atualidade, como comprovam as discussões em torno da alteração do Código Florestal Brasileiro (Brasil, 1965; Lei 4.771/65), a existência de normas jurídicas disciplinando a utilização de recursos naturais não é novidade no Direito (Sparovek et al. 2011). A institucionalização política e administrativa da proteção ambiental no Brasil se processou de forma lenta e gradual, consolidando-se somente na primeira metade do século XX. É somente na República que se inicia o estabelecimento de um ideário protecionista amparado legal e institucionalmente, que favoreceu a criação de áreas protegidas no país (Medeiros et al., 2004). Dentre as leis brasileiras que visam à conservação dos recursos naturais, destaca-se o Código Florestal Brasileiro, o qual conceitua e regimenta as Áreas de Preservação Permanente (APPs) e de Reserva Legal (RL) (Okuyama et al. 2012). Segundo Jacovine et al. (2008), apesar de as APPs e RLs serem protegidas por lei desde a promulgação do Código Florestal Brasileiro em 1965, sabe-se que o desrespeito à legislação é comum em todo o país, e devido à importância ambiental dessas áreas, torna-se necessário conhecer todos os possíveis obstáculos à sua efetivação.

As APPs são áreas estratégicas e de alta fragilidade ambiental que exercem papel importante na preservação de mananciais e recursos hídricos para garantir a estabilidade climática, hidrológica e geomorfológica, o fluxo gênico de fauna e flora e a proteção ao solo (Okuyama et al. 2012). As RLs são áreas designadas à conservação da biodiversidade e ao abrigo e proteção de fauna e flora nativas, e o uso sustentável dos recursos naturais são permitidos (Brasil, 1965). Esta gama de serviços ambientais, proporcionada por essas áreas protegidas, é considerada fundamental para o bem-estar da sociedade e o desenvolvimento econômico sustentável (Okuyama et al. 2012).

Para Houghton (1994), a conversão de áreas para atividades agropecuárias é o principal motivo de desmatamento em todo o mundo. Historicamente, o processo de colonização e consolidação do território brasileiro tem-se pautado na exploração predatória de seus recursos naturais, atingindo negativamente a qualidade e a disponibilidade dos recursos hídricos, principalmente os superficiais. Vastas extensões de matas exuberantes foram simplesmente suprimidas ao longo dos séculos para dar espaço à agricultura, pecuária e mineração
(Ribeiro et al., 2005).

Alterações nas dimensões de RL e APPs definidas no Código Florestal têm sido objeto de acalorados debates entre grupos ruralistas e ambientalistas nos últimos anos (Metzger, 2002). Um dos principais destaques no legislativo em 2012 foi a aprovação do Novo Código Florestal Brasileiro, Lei 12.651 de 25 de maio de 2012, após anos de muita discussão entre parlamentares, governo, ruralistas e ambientalistas (Martins, 2012). Em 17 de outubro de 2012 foi sancionada a Lei 12.727 com nove vetos da Presidenta Dilma Rousseff. Os dispositivos vetados tratam de várzeas (art. $4^{\circ}$ ), cômputo de APP e RL (art. $15^{\circ}$ ), de reflorestamento com frutíferas (art. $35^{\circ}$ ), implantação do PRA (Programa de Regularização Ambiental) (art. $59^{\circ}$ ) e dos parâmetros para recomposição de APP em áreas consolidadas (art. $61^{\circ}$-A e $61^{\circ}$-B). Este último ponto foi um dos mais delicados na discussão, pois envolve mudanças no escalonamento de faixas de recomposição de APP, em relação ao tamanho da propriedade (Martins, 2012). O artigo $83^{\circ}$ foi vetado por uma questão técnica legislativa, destacando que a alteração promovida pelo Congresso Nacional pretendia suprimir a exigência de averbação de RL, sem a existência de um sistema que substituísse esse importante instrumento.

No âmbito da educação ambiental, cabe destacar a necessidade de se trabalhar a importância das APPs e RLs com todo e qualquer cidadão, estimulando a valorização e mudanças na percepção e atitude individual e coletiva, em relação ao meio ambiente. $\mathrm{O}$ grande desafio consiste em se formular uma educação ambiental que seja crítica e inovadora, e, acima de tudo, um ato político voltado para a transformação social, cujo enfoque deve buscar uma perspectiva holística de ação, relacionando homem, a natureza e o universo, partindo do princípio de que os recursos naturais se esgotam e o protagonista da degradação é o homem (Jacobi, 2003). Conforme Souza et al. (2011), a educação ambiental pode contribuir no campo, especialmente nas áreas de assentamentos rurais, provocando as mudanças necessárias para uma melhor prática produtiva e adequada à conservação dos recursos naturais.

$\mathrm{O}$ incentivo à preservação de APPs e RLs em assentamentos se faz necessário, pois quando a conservação ambiental é levada em consideração, surge um aliado da produção e da qualidade de vida, em vez de um empecilho. A preservação nos assentamentos em Palmeira das Missões é particularmente importante, já que grande parte das áreas naturais do município já foram convertidas 
em pastagens e lavouras, e as APPs na região apresentam um percentual elevado de áreas irregulares, sem respeito à área de proteção prevista por lei. Deste modo, objetivou-se realizar atividades de conscientização ambiental nos Assentamentos Potreiro Bonito e Terra Nova, visando a promover e ampliar a troca de conhecimento sobre as APPs, RLs e os conflitos socioambientais, além incentivar a conservação e recuperação de APPs no município de Palmeira das Missões - RS.

\section{MATERIAL E MÉTODOS}

\section{Do Local}

As atividades foram realizadas em dois assentamentos, localizados no Município de Palmeira das Missões, inserido na Mesorregião do Noroeste do Rio Grande do Sul (Figura 1A), região fisiográfica do Alto do Uruguai, nas coordenadas $27^{\circ} 53^{\prime} 55^{\prime \prime} \mathrm{S}$ e $53^{\circ} 26^{\prime} 45^{\prime \prime} \mathrm{W}$, e altitude de $634 \mathrm{~m}$. O município possui uma área total de $1.419 \mathrm{~km}^{2}$ e uma população de 34.328 habitantes (IBGE, 2010). Apresenta clima subtropical, com temperatura média anual de $18^{\circ} \mathrm{C}$. O uso atual da terra compreende principalmente plantação de soja, seguido de milho e feijão. Também é base econômica a atividade leiteira. Observa-se a ocorrência de voçorocas de grandes dimensões em diversos pontos do município, o que evidencia mau uso da terra nesses locais (Figura 1B).

\section{Assentamento Potreiro Bonito}

O Assentamento Potreiro Bonito foi instituído em novembro de 1981, localizado entre Palmeira das Missões e Sarandi, próximo à BR 386. Possui um total de 164,11 ha e capacidade para 12 famílias, perfazendo um total de 13,67 ha de área média por família.

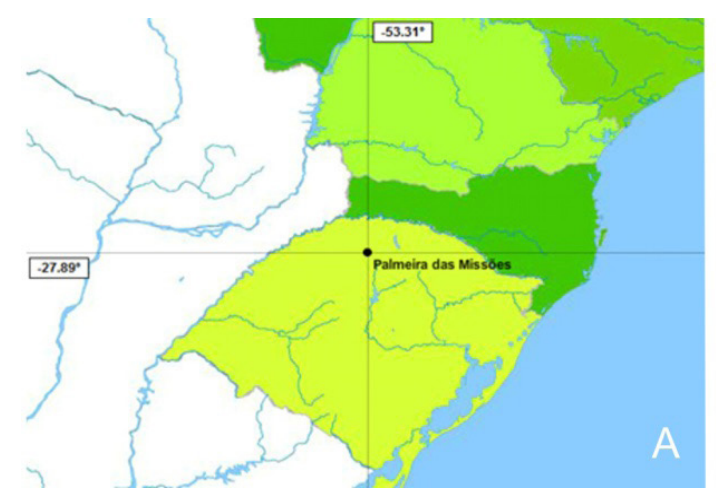

\section{Assentamento Terra Nova}

O Assentamento Terra Nova foi instituído em 10 de maio de 2001, servido pela BR 158, até o trevo que vai para Santa Bárbara do Sul, depois são mais $14 \mathrm{~km}$ por estrada de chão. Não possui estradas internas, dificultando o acesso aos lotes. Trata-se de uma área rural com um total de 399 ha, que possui capacidade para 27 famílias totalizando uma média de área por família igual a 14,77 ha.

\section{Das atividades}

A mobilização dos assentados para a participação nas atividades foi realizada com o auxílio da EMATER-Palmeira das Missões, uma Instituição de Assistência Técnica e Extensão Rural que promove o desenvolvimento rural sustentável. Foram realizadas duas palestras sobre o tema APP e RL, uma no dia 29 de maio de 2012 no Assentamento Terra Nova e outra no dia 31 de maio de 2012 no Assentamento Potreiro Bonito. As palestras foram realizadas com auxílio de aparelho multimídia e cartazes e abordaram a importância ambiental das APPs e RLs e as mudanças recentes na legislação ambiental, em especial o Novo Código Florestal Brasileiro, o qual estava sendo debatido no Congresso Nacional na ocasião. Cada palestra foi seguida de um momento para questionamentos, esclarecimentos de dúvidas e troca de experiências.

Após o momento de integração, foi aplicado um questionário aos participantes, com questões objetivas e discursivas, visando avaliar o conhecimento e opinião dos produtores rurais sobre o tema. Para finalizar as atividades, foram distribuídas 50 mudas de árvores nativas, como um gesto simbólico de incentivo à recuperação de APPs impactadas, pertencentes às seguintes espécies: Eugenia uniflora Leaf. (pitanga), Handroanthus heptaphyllus (Vell.) Mattos (ipê-roxo), Parapitadenia rigida (Benth) Brenan (angico-vermelho) e Patagonula americana L. (guajuvira).

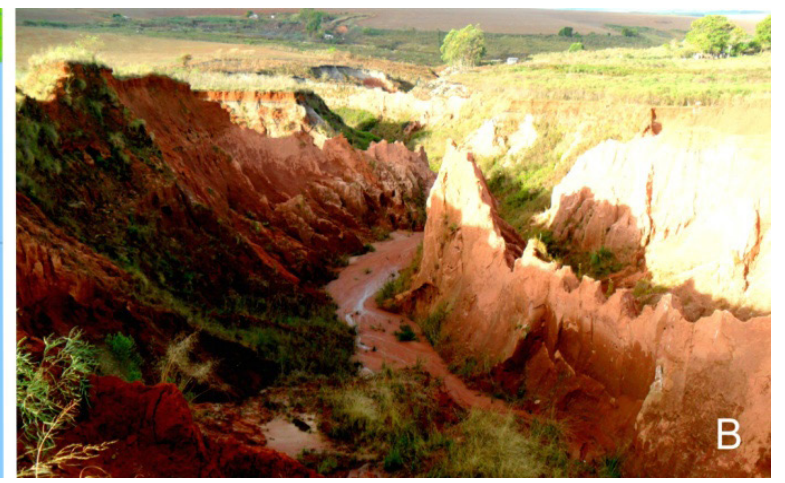

Figura 1: A. Localização do município de Palmeira das Missões na Mesorregião Noroeste do Rio Grande do Sul. B. Voçoroca localizada no município, próximo ao Assentamento Terra Nova. Fonte IBGE (2010) 


\section{RESULTADOS E DISCUSSÃO}

Segundo a EMATER- Palmeira das Missões, até o ano de 2008, havia 311 assentamentos de reforma agrária no Rio Grande do Sul, criados e reconhecidos pelo Instituto Nacional de Colonização e Reforma Agrária- INCRA, sendo três em Palmeira das Missões. O Assentamento Potreiro Bonito e Terra Nova de Palmeira das Missões estão sob responsabilidade do estado do RS, juntamente com outros 167 assentamentos.

As famílias dos Assentamentos Potreiro Bonito e Terra Nova chegaram progressivamente a Palmeira das Missões a partir do ano de 1981 e 2001, respectivamente, oriundas de municípios da região norte do estado. Tais famílias encontravam-se socialmente excluídas, devido às mesmas não terem condições de adquirir áreas de terra para produzir. Após a organização através do movimento dos trabalhadores sem-terra (MST), conquistaram o direito de trabalhar e produzir no campo. Uma vez instalado no seu lote, cada agricultor faz a gestão ambiental do território através de diferentes usos do solo que ele define. As suas escolhas relacionadas ao espaço, intensificação da produção e conservação ambiental dependem do mercado agrícola, legislação ambiental e acesso a créditos. Nos Assentamentos Potreiro Bonito e Terra Nova, a combinação desses fatores jun- tamente com a dificuldade de tornar rentável o trabalho contribui com o desmatamento de forma significativa. Portanto, a rentabilidade da produção para sobrevivência da família tem prioridade em relação a preservação ambiental.

Dezoito assentados participaram das atividades propostas, sendo onze do Assentamento Terra Nova e sete do Assentamento Potreiro Bonito (Figura 2 A-D). A faixa etária dos participantes variou entre 19 e 84 anos.

Nas palestras, os principais questionamentos dos produtores foram referentes às mudanças nas medidas mínimas de APPs e RLs no Novo Código Florestal Brasileiro. Através da avaliação dos questionários e da participação nos debates após as palestras, evidenciou-se que aproximadamente $80 \%$ dos participantes possuíam conhecimento anterior sobre o assunto, mas permaneciam com muitas dúvidas referentes às medidas previstas em lei para APPs e RLs em situações especiais. Quanto aos possíveis benefícios do Novo Código Florestal Brasileiro, os assentados afirmam que conhecem a importância da preservação das APPs, entretanto, eles demonstraram desinteresse em conservar essas áreas, devido a serem pequenos produtores e necessitarem destinar toda a propriedade para atividades agrícolas. Para muitos dos agricultores assentados, a polêmica no assunto do Código Florestal trata apenas de interesses políti-
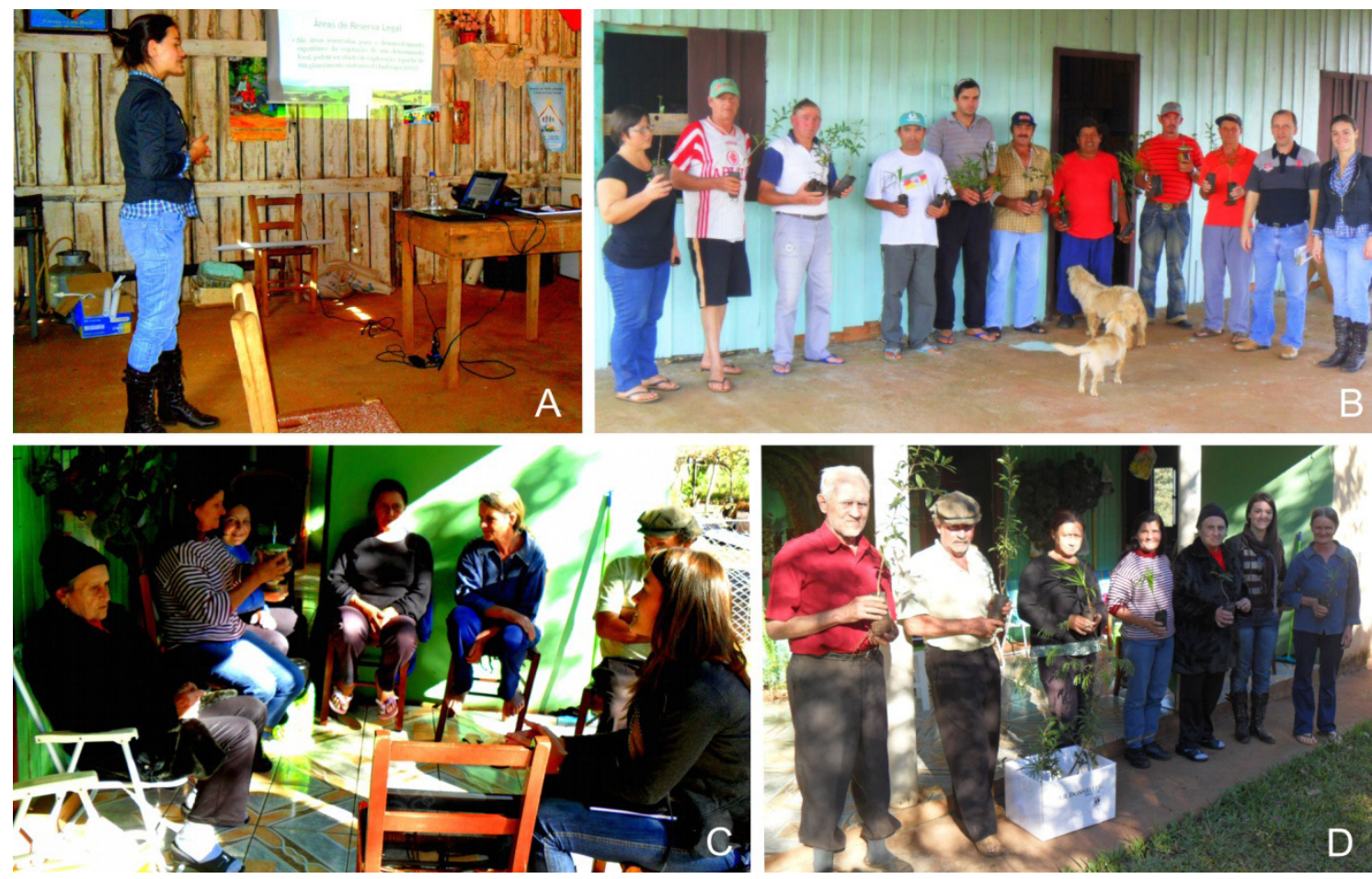

Figura 2: Atividades realizadas nos assentamentos em Palmeira das Missões, RS. A. Palestra realizada com a participação de famílias do Assentamento Terra Nova. B. Distribuição de mudas de árvores nativas no Assentamento Terra Nova. C. Encontro realizado no assentamento Potreiro Bonito. D. Distribuição de mudas de árvores nativas no Assentamento Potreiro Bonito. 
cos e econômicos das elites dominantes, e alguns acreditam que esse código é "uma bobagem". Essa manifestação de alguns produtores chama a atenção para a necessidade de os trabalhos de educação ambiental não serem realizados de modo ingênuo e descontextualizado.

Conforme os Parâmetros Curriculares Nacionais (PCN, 1998) a perspectiva ambiental consiste num modo no qual se evidenciam as inter-relações e a interdependência dos diversos elementos e manutenção da vida, à medida que a humanidade aumenta sua capacidade de intervir na natureza para satisfação de necessidades e desejos crescentes, surgem tensões e conflitos quanto ao uso do espaço e recursos. Os temas transversais referem-se às questões contemporâneas de relevante interesse social, capazes de atingir as diversas áreas do conhecimento. A educação ambiental postula-se dentro de uma concepção de construção interdisciplinar, visando à consolidação da cidadania a partir de conteúdos relacionados aos interesses e cotidiano da população. Para isto, ela fundamenta-se em três perspectivas teóricas emergentes: a pedagogia crítica, o pensamento complexo e o construtivismo num sentido amplo do termo (Roosevelt, 2003). Para estimular a percepção da população, é imprescindível ter um mediador que fará o elo entre a ciência e a conservação ambiental, cujo trabalho deve estar embasado na participação, conscientização, pensamento crítico-reflexivo, responsabilidade e transformação social.

Conforme Martins (2012), o Novo Código Florestal Brasileiro trouxe uma proporção de recuperação para que o pequeno produtor possa permanecer no campo. Segundo esse autor, no antigo Código havia situações em que $80 \%$ a $90 \%$ de algumas pequenas propriedades situavam-se em APPs, tornando a produção agrícola inviável. Entretanto, a questão ambiental não pode ser esquecida para que no futuro tais propriedades não sofram prejuízos ambientais os quais também refletem na produção, tais como redução na disponibilidade de água, assoreamento dos rios e degradação do solo.

Tanto a palestra como a discussão sobre os questionamentos foram bem aceitas pelos produtores rurais, pois os mesmos puderam interagir e adquirir novos conhecimentos e expor suas experiências e realidade ocorridas no assentamento. Mais do que conscientizar, as atividades contribuíram com o aprendizado dos próprios proponentes das atividades, os quais puderam constatar que mudanças de estratégias nas ações de educação ambiental são mais do que necessárias.
Em concordância com Martins \& Frota (2012), os quais identificaram a necessidade de novas tendências na educação ambiental em escolas de Santa Catarina, percebeu-se que a educação ambiental não formal também requer mudanças, tais como ações de longo prazo e melhor contextualizadas. $\mathrm{Na}$ situação em questão, a inclusão de informações sobre a viabilidade de produção sustentável, com exemplos práticos, traria resultados muito positivos.

Iniciativas como projetos de extensão rural com foco em manejo integrado e conservação ambiental são fundamentais para a introdução e melhorias no sistema de manejo dos recursos naturais no âmbito da propriedade rural e potencializam os serviços ambientais prestados pelas áreas destinadas as APPs e RLs (Okuyama et al. 2012). Com relação à educação ambiental e à percepção ambiental, Marques (2001) considera estes dois conceitos como armas importantes na defesa do meio ambiente, ajudando a reaproximar o homem da natureza e, por consequência, promover a garantia de um futuro com qualidade de vida para a população. Já, com referência à legislação ambiental no meio rural, pode-se notar que os produtores acreditam na importância da exigência no cumprimento da lei das APPs e RLs para preservação do meio ambiente, entretanto, a preocupação central nas falas é como manter a produção e a preservação nas propriedades.

Ações coercitivas por parte do Estado não se têm mostrado suficientes para cumprimento da legislação ambiental referentes às APPs e RLs. Conforme Campos et al. (2002), essas áreas, especificamente as RLs, são plausíveis de uso, exercendo função no fornecimento de bens econômicos de forma sustentável, desde que não se pratique o corte raso. Ainda que sua importância ambiental e seu potencial econômico sejam reconhecidos pela sociedade, o fato é que existem barreiras culturais, normativas, técnicas e econômicas para que sejam cumpridas as leis pelos agricultores. No caso de pequenos produtores familiares, esse problema tende a se agravar, devido à disponibilidade de área ser reduzida para o cultivo e sobrevivências da família (Ramos, 2004).

A disseminação de informações sobre os benefícios da recuperação das áreas degradadas é uma importante ação na mobilização para adoção de práticas conservacionistas. Tentou-se mostrar ao produtor rural que ele não pode ficar alheio à legislação, devendo conhecer e se preocupar com seus direitos e deveres de cidadão. O conhecimento dos agricultores sobre a conservação das APPs é 
visível. Todos possuem uma relação direta com o ambiente e dependem dele para manter sua produção. Então, uma proposta de educação ambiental foi dirigida aos assentamentos, tentando despertar o interesse do assentado em participar diretamente de um processo de produção em harmonia com o meio ambiente.

Procurou-se demonstrar aos produtores que ações de recuperação e preservação, tanto em APPs como em RLs, podem ser atreladas a formas de aproveitamento econômico. A experiência mostrou que, no contexto atual, torna-se infrutífero falar com produtores sobre estes temas, meramente pelo restabelecimento dos serviços ambientais. Neste sentido, para que a sociedade alcance um desenvolvimento sustentável, é necessário que haja uma mudança na percepção e nos valores nestes produtores, individualmente e coletivamente. $\mathrm{E}$ para atingir esse objetivo, faz-se necessário promover o diálogo, utilizando diferentes formas de compartilhar as informações, voltadas para os interesses e inquietações de cada grupo.

\section{CONCLUSÃO}

Considerando a urgência em estabelecer práticas que contribuam na conservação da biodiversidade, do solo e da água, em particular nas APPs e RLs, há necessidade de que sejam implementados mais projetos que visem à educação ambiental, capazes de promover o diálogo e a colaboração entre a comunidade científica e a comunidade em geral, as quais muitas vezes atuam de modo desarticulado. Além disso, ações de conservação e recuperação de APPs e RL devem ser realizadas sempre integradas com atividades preparatórias e posteriores de educação ambiental.

Apesar de transformações significativas estarem ocorrendo nas últimas décadas no meio rural, a visão predominante dos produtores ainda é a de que preservar a natureza é sinônimo de prejuízo econômico. Neste contexto, a preservação ambiental somente é levada a sério com a imposição de leis punitivas, pois a maioria dos agricultores não percebe o real benefício advindo desses processos. As mudanças de comportamento advindas de punições não possuem, entretanto, efeitos duradouros, muitas vezes havendo o abandono da causa quando são encontradas brechas na lei ou quando há sua flexibilização. Portanto, fica evidente a importância de trabalhar e investir continuamente em educação ambiental, seja no âmbito formal ou não-formal, principalmente através de projetos ou programas de longo prazo, visto que as ações pontuais e fragmentadas não têm surtido os efeitos desejados.

\section{AGRADECIMENTOS}

Os autores agradecem ao escritório municipal da EMATER de Palmeira das Missões/RS, especialmente ao Sr. Renato R. Serfini pelo auxílio na mobilização dos agricultores e por ter permitido e viabilizado a realização destas atividades nos assentamentos. Agradecemos também ao Sr. Paulo Oscar de Deus Lima pelo acesso aos dados sobre os assentamentos, e à Profa. Dra. Tânea M. B. Garlet pelas leitura do manuscrito e pelas sugestões.

\section{REFERÊNCIAS BIBLIOGRÁFICAS}

BRASIL. Código Florestal Brasileiro. 1965. Lei Federal $\mathrm{n}^{\circ}$ 4.771. Brasília.< http://www.planalto.gov. br/ccivil 03/Leis/L4771.htm>. 25/01/2013.

CAMPOS, J. B; COSTA, F. L.V.; NARDINE, M. $M$. Recuperação da reserva legal e conservação da biodiversidade. Cadernos de Biodiversidade, v. 3 , n.1, p. 1 - 3, 2002.

HOUGHTON, R. A. A extensão global de mudanças no uso da terra. Bioscience, v. 44, p. 305 - 315, 1994.

IBGE. Instituto Brasileiro de Geografia e Estatística. Contagem da População 2010. Disponível em: http://www.ibge.gov.br/cidadesat/painel/painel. php?codmun $=431370$. Acesso em 10/05/2013.

JACOBI, P. Educação Ambiental, Cidadania e Sustentabilidade. Cadernos de Pesquisa, São Paulo, $n$. 118, p. $8-17,2003$.

JACOVINE, L. A. G.; CORREAA, J. B. L.; SILVA, M. L.; VALVERDE, S. R.; FILHO, E. I. F.; COELHO, F. M. G.; PAIVA, H. N. Quantificação das áreas de preservação permanente e de reserva legal em propriedade da bacia do Rio Pomba - MG. Revista Árvore, v. 32, n. 2, p. 269 - 278. 2008.

MARQUES, D. V. Uma proposta de educação ambiental para áreas verdes: o exemplo do bosque John Kennedy, Araguari, MG. 2001. Monografia (Curso de Graduação em Geografia). Universidade 
Federal de Uberlândia, Uberlândia.

MARTINS, C. Reflexos do novo Código Florestal Brasileiro sobre a pequena propriedade: o caso do assentamento Rondinha no Município de Jóia - RS. 2012. p. 13-15. Monografia (Curso de graduação em Geografia). Universidade Regional do Noroeste do Estado do Rio Grande do Sul - UNIJUÍ, Ijuí.

MARTINS, M. C.; FROTA, P. R. O. Novas Tendências em educação ambiental. In: MENDONÇA, A. W., SIQUEIRA, A. B.; MARCOMIN, F. E. (Orgs.). Educação, Sociedade e Meio Ambiente no Estado de Santa Catarina: múltiplas abordagens. São Leopoldo: Oikos, 2012. p. $39-50$.

MEDEIROS, R.; IRVING, M.; GARAY, I. A proteção da natureza no Brasil: evolução e conflito de um modelo em construção. Revista de Desenvolvimento Econômico, v. 6, n. 9, p. 83 - 93, 2004.

METZGER, J. P. Bases Biológicas para a reserva legal. Ciência Hoje, v. 31, n. 183, p. 48 - 49. 2002.

OKUYAMA, K. K; ROCHA, H. C.; NETO, W. H. P; ALMEIRA, D.; RIBEIRO, D. R. S. Adequação de propriedades rurais ao Código Florestal Brasileiro: Estudo de caso no estado do Paraná. Revista Brasileira de Engenharia Agrícola e Ambiental, v.16, n. 9, p.1015- 1021, 2012.

Parâmetros Curriculares Nacionais: terceiro e quarto ciclos: apresentação dos temas transversais. 1998. Secretaria de Educação Fundamental. Brasília: $\mathrm{MEC/SEF}$.

RAMOS, F. L. O.; FRANSCICO, C. E. S. Legislação florestal, sistemas agroflorestais e assentamentos rurais em São Paulo: restrições ou oportunidades? In: CONGRESSO BRASILEIRO DE SISTEMAS AGROFLORESTAIS, 5., 2004, Curitiba, PR. SAFs: desenvolvimento com proteção ambiental: anais... Curitiba: Embrapa Florestas, 2004. p. 211-213.

RIBEIRO, S.R.D. 2012. Adequação de propriedades rurais ao Código Florestal Brasileiro: Estudo de caso no estado do Paraná. Revista Brasileira de Engenharia Agrícola e Ambiental, v.16, n.9. p. 10151021.

RIBEIRO, C. A. A. S.; SOARES, V. P.; OLIVEIRA, M. S.; GLERIANI, J. M. O desafio de delimitação de áreas de preservação permanente. Revista Árvore, v. 29 , n. 2 , p. $203-212,2005$.

ROOSEVELT, F. S. Uma experiência em Educação Ambiental: formação de valores socioambientais. 2003. 125 p. Dissertação de Mestrado (Departamento de Serviço Social). Pontifícia Universidade Católica do Rio de Janeiro, Rio de Janeiro.

SOUZA, J. C. M.; GONÇALVES, L.; SOARES, A. M. D. A Educação Ambiental na recuperação e conservação de recursos naturais: a percepção de assentados rurais no cerrado goiano. Revista de Geografia Agrária, v. 6, n. 11, p. 312 - 337, 2011.

SPAROVEK, G.; BARRETTO, A.; KLUG, I.; PAPP, L.; LINO, J. A revisão do Código Florestal. Novos estudos - CEBRAP, n. 89, p.111 - 135, 2011. 